\title{
Server Operated Easy Payment in Shopping Mall
}

\author{
Subham Agarwal, Prakhar Rai, Manish Kumar, Adarsh Kashyap, Shubham Swaraj
}

School of Computer Science and Engineering, Lovely Professional University, Phagwara, Punjab, India

\section{ABSTRACT}

Article Info

Volume 7, Issue 2

Page Number: 634-639

Publication Issue :

March-April-2021

\section{Article History}

Accepted : 25 April 2021

Published : 30 April 2021
In today's' era we see a huge crowd in the shopping malls. This is due to the growing population and the less numbers of billing counters in the shopping mall. The customers waste a lot of expensive time standing in the queue for billing. Keeping this in mind the idea of "SERVER OPERATED EASY PAYMENT IN SHOPPING MALL" is originated. This is also named as "EASY PAY". An application is designed which holds the product. The customer can add the products to the cart of his/her choice. The total bill calculation is done by the application itself. After buying, a payment page pops up which allows the customer to make his payment then and there. This reduces the time of standing in queue. The payment is sent to the database we designed, which is connected to the application. The database holds the record of every customer which a unique customer Id to ensure safety of every customers. At the other end the security checker matches the product bought by customers by matching the Id with the database to ensure safety and stealing of products. This saves the time of the customer and he have to not stand in queue anymore for billing. This idea defines that how internet and technology can change the world if used in a proper manner.

Keywords : Shopping Mall, human lifestyle, human lifestyle

\section{INTRODUCTION}

In this present year's human lifestyle has been moving faster than the earth. Humans have shape and extended themselves by the virtue of technical tools and art works. Human beings are always trying to develop technology that will fulfill their basic needs in an easier and faster way. Time files like an arrow. So people are not able to spend more time in shopping. Due to this people prefer shopping malls which is used for getting their daily needs. Even though shopping mall gives the benefit of saving time, but people have only time in weekends to visit the shopping malls. The customers have to stand in billing lines for long time in a queue than actual shopping time. So people find difficulties at the cash counter.

In extensive, Indian population is increased and everyone is moving towards smart shopping. Though the online shopping makes everything easy but people find difficulties in online shopping. This is because sometimes, the original products get replaced by the other product or sometimes the product is broken or leaked during the delivery time. In shopping mall the people have to stand in queue for billing after the purchasing. The person in the billing section will scan the barcode of each and every

Copyright: (C) the author(s), publisher and licensee Technoscience Academy. This is an open-access article distributed under the terms of the Creative Commons Attribution Non-Commercial License, which permits unrestricted non-commercial use, 
product and provide the correct bill to the customer. One disadvantage is that they cannot buy the product which don't have the barcode in it even though the customers want it. This make the customers desire in vain. This process is tedious and it becomes a trash on holidays. "Time is Technology". So we have introduced a server operation with different techniques till date to solve the problems. There are a number of methods to design carts which makes the customers shopping easier and faster for the customers in the mall by avoiding the requirements to stand in long billing process. And for the security purpose we are using a Unique client Id and a checker data system at the security gate. The security checker checks the items of the person that the customer has bought with the information that has stored in the database and will also check whether the payment has been done or not. If the payment is done the application will show that the payment is success and customer can check out from the shopping mall. This ensures the safety of money and items.

\section{PROPOSED SYSTEM}

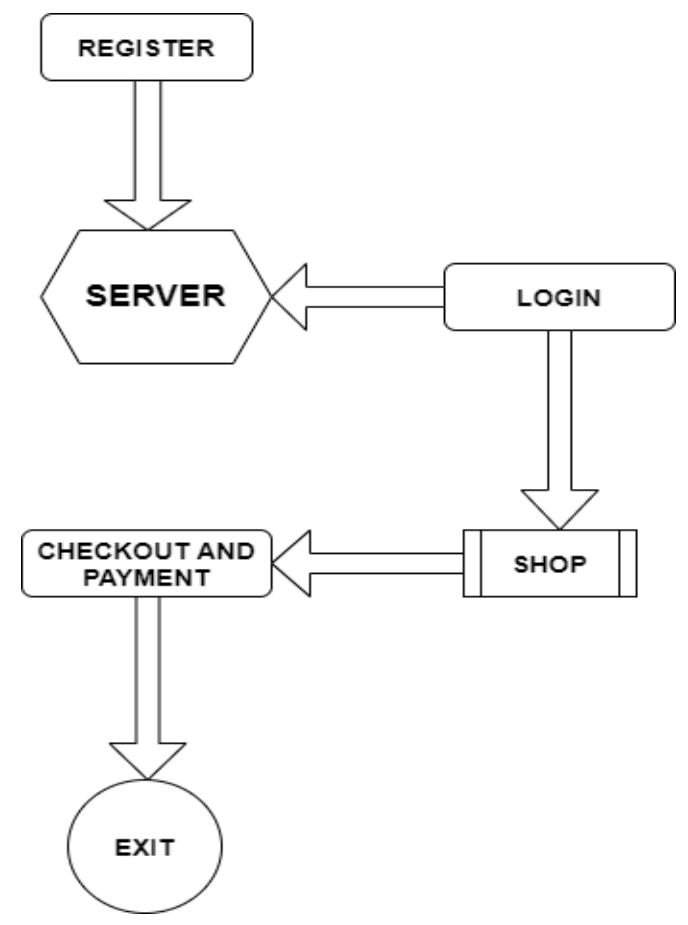

In order to be customer friendly we have designed a registration portal for customer where customer can register with us if they don't have an id in our portal. This helps them to keep updated of every changes we do in our shopping system .

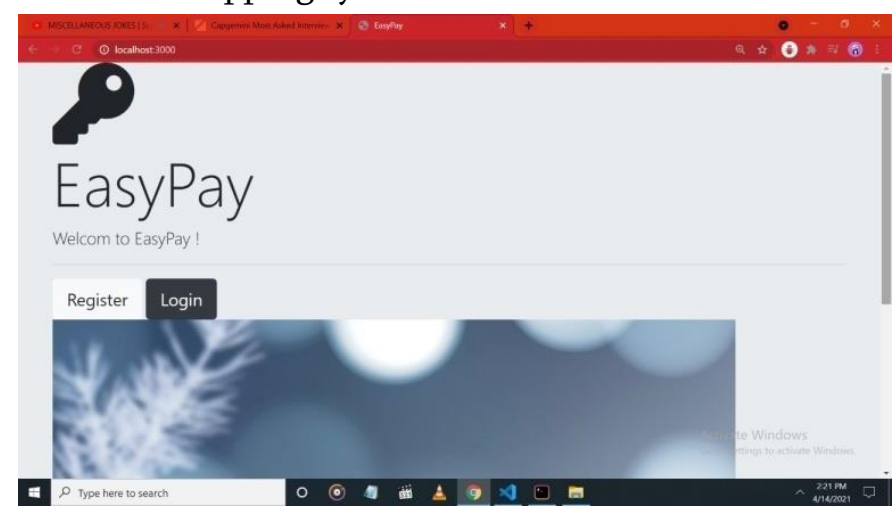

Figure 1. Registration Screen

The customer can register with us by entering his/her detail and can become a member. Once customer is registered with us, the customer can login to the page and can add products that the customer see's in the shopping cart. We have introduced this feature to ensure customer friendliness and to know the movement of every customer that who is doing what?. We have designed an encrypted password format which will be stored in the hash format that keeps the customer's privacy. The next step would be to login to the portal.

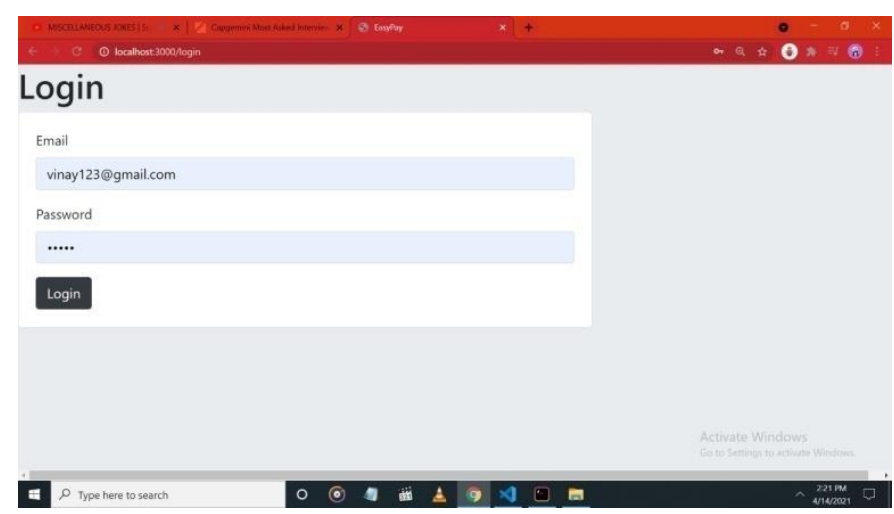

Figure 2. Login page

Once the customer login's, the customer will be able to go to the cart option to add the products that the customer wants to purchase. The customer will see an option of ADD PRODUCTS to which the customer can click to continue. 


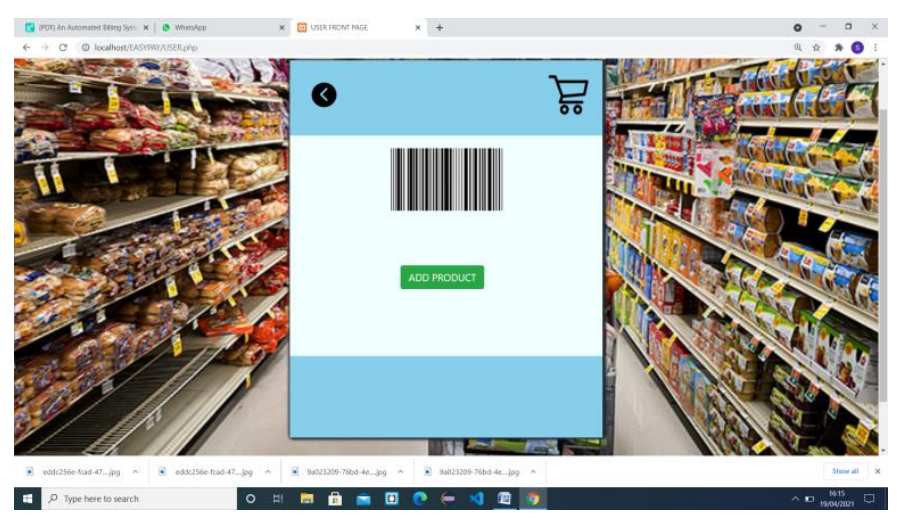

Figure 3. Add Products page

\section{CART FUNCTIONING}

SHOPPING CART :- A shopping cart is necessary to hold the items that the customer wants to purchase for an easy checkout.

When the customer clicks on the ADD PRODUCTS page they will land in the main page of items. The items are of groceries type. The customer selects the product and clicks on "ADD TO CART" below the product. The product gets added to the cart. If the customer tries to enter a product more than once in the cart. The message pops up stating that "ITEM ALREADY ADDED." And on adding every product they get a message of "ITEM ADDED" to ensure that everything is going fine.

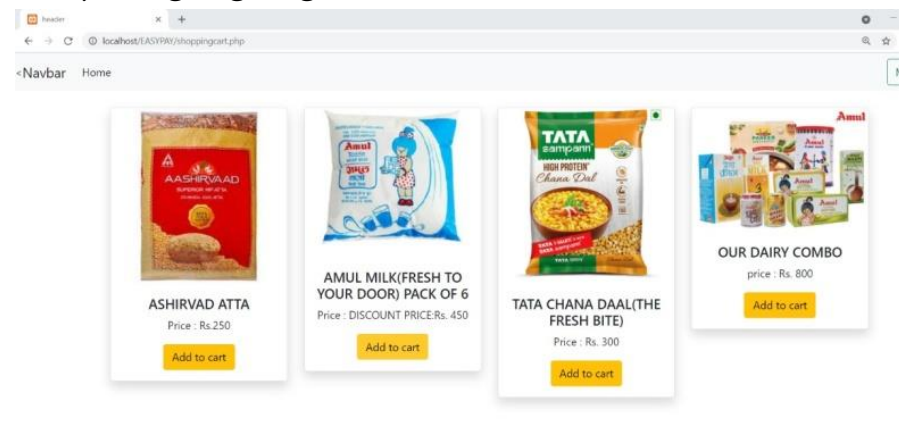

व

Figure 4. Product details and cart option

The Cart option will be visible to the top right side of the page. The maximum limit will be 10 for every item, which is the default stock we have entered. If the items get emptied from the shopping mall and no stock is left, the backend engineering team can remove the product or can hide them. The customers will not be able to see that product again. We can also increase the quantity of the stock to more than 10 depending on the stock we have and that will be reflected to the customer or the customer who is buying the product. The customer can go to the cart page on the top right side to see what products they have add to their cart. After adding the product, if a customer feels like they don't want to buy the product, they can simply click on remove button adjacent to the price of every item. The item will be removed form the shopping cart for them. The another interesting feature is the auto bill calculator. After adding the products the total is done by the application itself and is reflected in the right side of the table. The calculator is well tested and always produces satisfactory results. So the customers need not to recheck every time if they have got the right total or not.

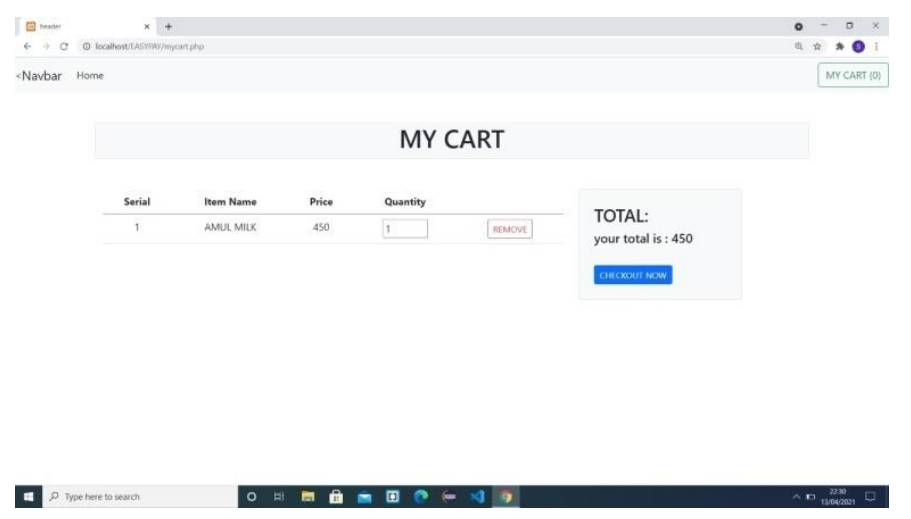

Figure 5. A Cart with item

The figure above shows the cart with one item. The grand total is reflected on the right side and the button highlighted in the blue takes the customer to the payment page option/checkout.

\section{PAYMENTS CHECKOUTS AND RESULTS}

The exit/checkout is kept very simple and friendly. Once the customer gets the total than the customer is able to checkout. The customer needs to click checkout and a checkout form will open for the customer. In the form the customer needs to enter his 
name, email so that we can contact him later in future to send notifications or for any other purpose. The customer will also have to enter the price that they are paying. The customer needs to add the quantity of items that they have purchased. This information will get stored in the database and if at the security check any mismatched is found any action may be taken accordingly. The security checker will open his portal where he will get the details of the particular customer that what they have purchased and in how much quantity.

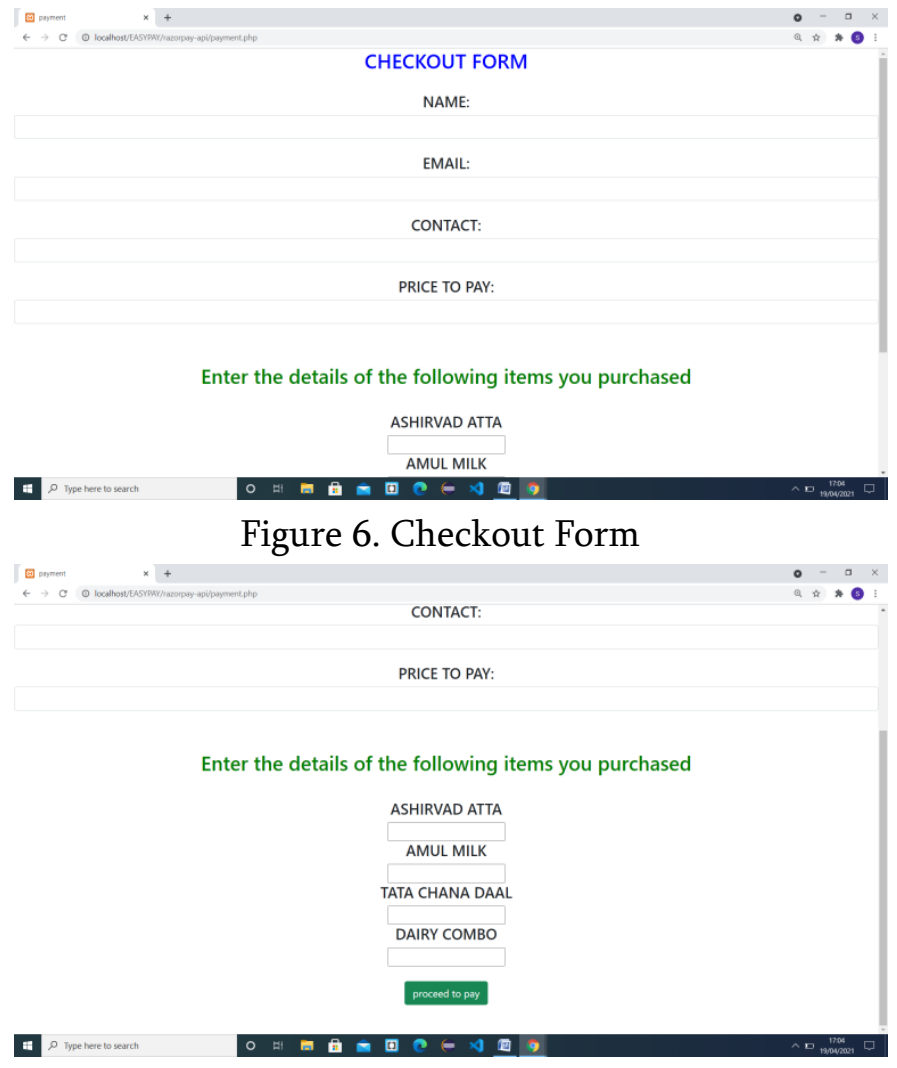

Figure 7. Checkout form

After entering the details the customer sees a button highlighted in green called" PROCEED TO PAY". Once the customer clicks on proceed to pay he will see the payment screen of our title named as" EASYPAY", to ensure that they are paying to the authorized and correct circle.

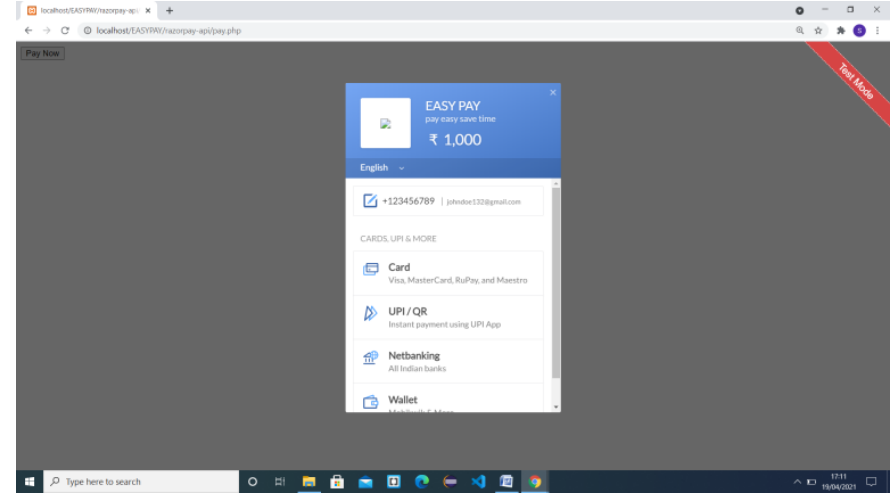

Figure 8. Payment page

The amount will be fetched from the form where the customer already entered the price. Like in this case in the above figure amount 1000/- is fetched as the customer shopped a total of 1000 . The customer can use net banking and so on to make payments.

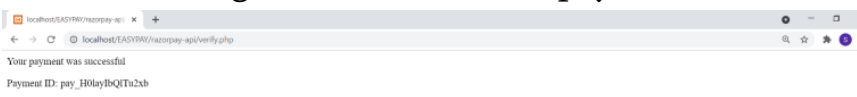

a

Figure 9. Payment success page

After paying the customer will get a message stating that the payment was successful. A unique ID will be generated to check later that this payment was done by whom as we will have multiple payments from different customers. At the other end the security checker will login in his account to see whether the money has been deposited in the account or no. If the payment is successful than he will let the customer to go. And if the payment is failed than he can stop the customer from purchasing or not letting him go etc. 


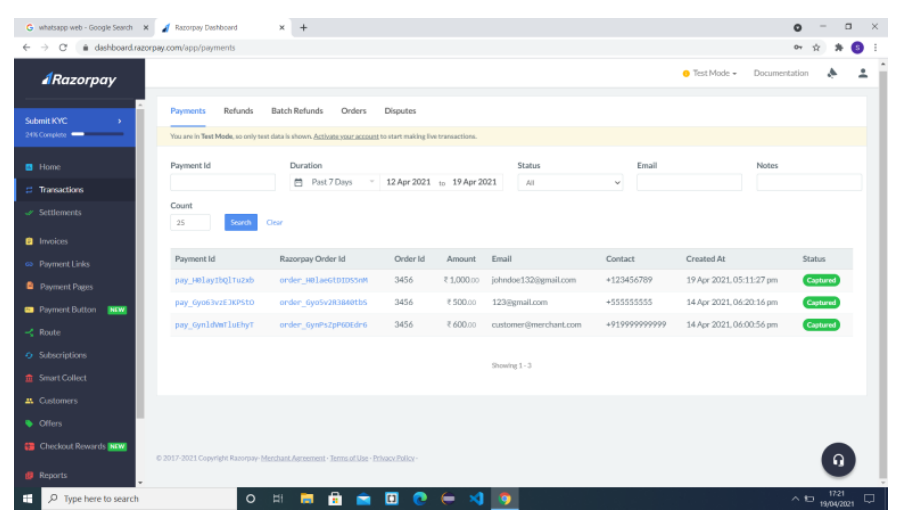

Figure 10. Payment in account confirmation page The above page shows that the customer named " john doe" has successfully paid to EASYPAY an amount of 1000. 3 transactions have been made so far. As the customer increases the transaction will keep increasing. For the payment gateway, we have used razor pay payment gateway integration which ensures the type safety of every customers and has been trusted since years. Every minute details are tracked like the time of transaction and date of transaction, so that the customer cannot play fool by showing some old transaction of same amount. This ensures safety in every possible way.

\section{CONCLUSION}

In this paper we proposed a secure smart shopping system utilizing a smart server and a easy payment method. This project enhances the security and payment issues as discussed in the shopping system. We detail the design of a complete system and build a prototype to its functions. We believe that the future stores will be packed with the smart payment in the shopping malls and where ever possible. Our future work will focus on improving the current project by including RFID kind of things for which we already begin the journey. For example Scan and pay etc.

\section{REFERENCES}

[1]. Kumar R, Krishna KG, Ramesha K. Intelligent Shopping Cart. International Journal of
Engineering Science and Innovative Technology (IJESIT). 2013 Jul; 2(4):1-9.

[2]. Pawar, Shilpa D., et al. "Wi-FI Cloud server based User Operated Billing System in Mall." 2020 5th International Conference on Communication and Electronics Systems (ICCES). IEEE, 2020

[3]. Kalaivani, P., C. Rajan, and S. Sandhiya. "An Automated Billing System in Shopping Malls Using Bascart." Bulletin of Scientific Research 1.1 (2019): 62-68.

[4]. Arora, Jatin, S. J. Gagandeep, and Ravinder Kumar. "Smart Goods Billing Management and Payment System for Shopping Malls." International Journal of Engineering \& Technology 7.2.7 (2018): 456-461.

[5]. B. Ananthabarathi, "High Speed Billing System in Departmental Stores" Middle-East Journal of Scientific Research, pp. 1828-1832, 2012.

[6]. Chandrasekar, P., and T. Sangeetha. "Smart shopping cart with automatic billing system through RFID and ZigBee." International Conference on Information Communication and Embedded Systems (ICICES2014). IEEE, 2014.

[7]. Ankit Anil Agarwal, Saurabh Kumar Sultania, Gourav Jaiswal and Prateek Jain on "RFID Based Automatic Shopping Cart" in Control Theory and Informatics; ISSN 2224-5774 (print) ISSN 2225-0492 (online),Vol 1, No.1, 2011

[8]. Maini E, Sheltar J. Wireless Intelligent Billing Trolley for malls. International Journal of Scientific Engineering and Technology. 2014 Sep; 3(9):1175-78.

[9]. J.Thangakumar, S. Sainath, K. Surender, V. Vikram Arvind, "Automated Shopping Trolley for Super Market Billing System”International Journal of Computer Applications (0975 8887) International Conference on 
Communication, Computing and Information

Technology (ICCCMIT-2014)

[10]. H. Karl and A. Willig, "Protocols and Architectures for Wireless Sensor Networks," Chichester, England, 2005.

[11]. Mayur Chaudhari, Amit Gore, Rajendra Kale and S.H. Patil, "Intel-ligent Shopping Cart with Goods Management Using Sensors", International Research Journal of Engineering and Technology (IR-JET), Volume 3 Issue 05 May 2016.

[12]. S.Rohith and C Madhusudan, "Easy Billing System at Shopping Mall Using Hitech Trolly", International Journal \& Magazine of Engineering, Technology, Management and Research, Volume 2, Issue 7, July 2015.

[13]. Y. J. Zuo "Survivable RFID systems: Issues, challenges, and tech-niques", IEEE Trans. Syst., Man, Cybern. C, Appl. Rev., vol. 40, no. 4, pp.406 -418, 2010.

\section{Cite this article as :}

Subham Agarwal, Prakhar Rai, Manish Kumar, Adarsh Kashyap, Shubham Swaraj, "Server Operated Easy Payment in Shopping Mall", International Journal of Scientific Research in Computer Science, Engineering and Information Technology (IJSRCSEIT), ISSN : 2456-3307, Volume 7 Issue 2, pp. 634-639, March-April 2021. Available at doi : https://doi.org/10.32628/CSEIT2172140 Journal URL : https://ijsrcseit.com/CSEIT2172140 